\title{
Evaluation of Carvedilol in Prevention of First Attack of Variceal Hemorrhage in Patients with Liver Cirrhosis
}

\author{
Ahmad Mahmod, Samy Essa, Eman Abdel Aal, Hosam Dawod \\ Tropical Medicine Department, Faculty of Medicine, Zagazig University, Egypt
}

Corresponding Author

Hosam Mohamad

Dawod Mobile:

+201113008201

E mail:

engfikry@yahoo.com

Received :3 / 4/2012

Accepted after

revision: $15 / 5 / 2012$

Key words: carvedilol propranolol - variceal band ligation.
Background and study aim: Carvedilol has beneficial effects on splanchnic haemodynamics following acute and chronic administration in cirrhosis. The aim of this study is to evaluate the role of carvedilol in prevention of first variceal bleeding in patients with liver cirrhosis and to compare its effect with that of variceal band ligation (VBL) and propranolol.

Patients and methods: Seventy five patients with liver cirrhosis and endoscopically proven esophageal varices (grade II or larger in size with or without variceal red color signs), that have not bled yet were randomized to either VBL performed every 2 weeks until varices were eradicated (25 patients), carvedilol $12.5 \mathrm{mg}$ once daily (25 patients) or propranolol titrated to reduce resting pulse by $>25 \%$ (25 patients) and followed

\section{INTRODUCTION}

A major cause of cirrhosis related morbidity and mortality is the development of variceal hemorrhage. Variceal hemorrhage occurs in 25 to 40 percent of patients with cirrhosis[1]. In the view of relatively high rate of bleeding from esophageal varices, an important goal of management of patients with cirrhosis is the primary prevention of variceal hemorrhage, therefore, all patients with cirrhosis should undergo diagnostic screening upper gastrointestinal tract endoscopy when cirrhosis is first diagnosed to document the presence of varices and to determine their risk for variceal bleeding. In patients with medium/large varices that have not bled either, nonselective Beta blockers (Propranolol or Nadolol) or variceal band ligation (VBL) is recommended for the prevention of first variceal bleeding and VBL should be considered in patients with up on the same schedule at 6 and 12 months.

Results: Carvedilol had lowest rate of the first variceal bleeding when compared with VBL and propranolol (10\%, 12\% and $20 \%$ respectively). Carvedilol had significantly decreased the percentage of patients with varices grade III or IV over the follow up period (from $40 \%$ to $24 \%$ ). Both carvedilol and propranolol significantly decreased severity of portal hypertensive gastropathy over follow up period. On the other hand, VBL significantly increased severity of portal hypertensive gastropathy.

Conclusion: Carvedilol is effective in preventing the first variceal bleeding. Carvedilol is an option for primary prophylaxis in cirrhosis and esophageal varices grade $\geq$ II in single daily dose of $12.5 \mathrm{mg}$.

contraindications, intolerance or noncompliance to beta blockers[2].

Carvedilol is a potent non cardioselective Beta-blocker with intrinsic anti-alpha1-adrenergic activity. Therefore, its effects mimic those of the combination therapy using propranolol and prazosin[3]. Furthermore, Carvedilol has beneficial effects on splanchnic haemodynamics following acute and chronic administration in cirrhosis, without compromising hepatic blood flow or renal function[4]. Low dose carvedilol $12.5 \mathrm{mg}$ is an extremely potent portal hypotensive pharmacological agent with minimal effects on systemic haemodynamics[5].

The aim of the study was to evaluate the role of carvedilol in prevention of first variceal bleeding in patients with liver cirrhosis and to compare its effect with that of propranolol and esophageal band ligation. 


\section{PATIENTS AND METHODS}

This study was conducted in the Tropical Medicine Department, Faculty of Medicine Zagazig University, between December 2008 and September 2011. Seventy five patients were selected with liver cirrhosis and endoscopically proven esophageal varices (grade II or larger in size with or without variceal red color signs), that have not bled yet.

Exclusion criteria were as follows; contraindications to Beta-blockers, serum creatinine greater than $2 \mathrm{mg} / \mathrm{dL}$, history of haematemesis and/or melena, history of sclerotherapy or band ligation, history of beta blockers intake, hepatoma, portal or hepatic vein thrombosis, tense ascites, presence of gastric or duodenal varices, severe erosive esophagitis, active duodenal or gastric ulceration, or gastrointestinal tract (GIT) tumor. Written informed consent was taken from each patient.

The patients were randomly distributed to 3 equal treatment groups. Group I included 25 patients who underwent endoscopic VBL. It was repeated every 2 to 4 weeks until esophageal varices became either grade I or complete obliteration. Group II included 25 patients who received carvedilol. It was started at a daily dose of $6.25 \mathrm{mg}$ at the morning. The dosage of carvedilol was increased after 1-2 weeks to a target dose of $12.5 \mathrm{mg}$ per day while heart rate is more than 55 beat per minute and systolic pressure is greater than $85 \mathrm{~mm} \mathrm{Hg}$. Group III included 25 patients who received propranolol. It was started at a dosage of $20 \mathrm{mg}$ twice daily and the dosage was stepwise increased every 1-2 weeks by $20-40 \mathrm{mg}$ as tolerated until the resting heart rate was reduced by $25 \%$ from base line or was approximately 55 beat per minute while systolic blood pressure was greater than 85 mmHg.

All the patients were subjected to full history taking, clinical examination, complete blood picture, liver and kidney function test, modified Child Pugh classification, abdominal ultrasonography, colored doppler portal vein, endoscopy at randomization time, 6 and 12 months.

Assessment of $1^{\text {st }}$ variceal bleeding in the three treatment groups was done during the follow up period (one year from a randomization time). Variceal bleeding is defined clinically by hematemesis and/or melena with endoscopic evidence of variceal hemorrhage (stigmata of recent hemorrhage on a varix and no other lesions) and at least a $2 \mathrm{~g} / \mathrm{dL}$ reduction in hemoglobin within 24 hours of admission.

\section{Statisitical analysis:}

Data were entered, checked and analyzed using Epi-Info version 6.02 and SPSS for windows version 8[6]. Baseline parametric data were expressed as the mean and standard deviation, and any differences in the groups were analyzed using an unpaired Student $t$ test. Differences in parametric data over time were analyzed using the paired sample $t$ test. Non parametric data were analyzed using the chi squared test Multilogistic Regression analysis and ROC curve were used to assess variables predicting the end points used cut off value.

\section{RESULTS}

There were no statistically significant differences among the three treatment groups regarding demographic and base line clinical data, laboratory, ultrasonographic data, portal vein congestion index (CI) (area /mean velocity), endoscopic findings and Child Pugh classification (table1). Serum creatinine level in propranolol group showed statistically significant increase over the follow period $(1.23 \pm 0.29$ at start of the study versus $1.41 \pm 0.40 \mathrm{mg} / \mathrm{dl}$ at 12 months, $\mathrm{P}=0.02)$. On the other hand, Serum creatinine was unaffected $(1.14 \pm 0.23$ versus $1.16 \pm 0.29 \mathrm{mg} / \mathrm{dl}, \mathrm{P}=0.21$ ) in carvedilol group. The portal vein congestion index (CI) significantly decreased over the follow up period in both carvedilol group $(0.183 \pm 0.09$ at randomization time to $0.152 \pm 0.01$ at 12 months with $\mathrm{P}=0.009$ ) and propranolol group ( $0.185 \pm 0.09$ at randomization time to $0.169 \pm$ 0.09 at 12 months with $\mathrm{P}=0.01)$. However, there was no significant change in the mean CI in VBL group $(0.176 \pm 0.08$ at 0 time to $0.171 \pm$ 0.02 at 12 months with $\mathrm{P}=0.86$ ).

Carvedilol had significantly decreased the number of patients with varices grade III or IV over the follow up period (from $40 \%$ to $24 \%$ ). On the other hand, proranolol had no significant change in the number of patients with varices grade III or IV. Both carvrdilol and proranolol significantly decreased the number of patients with moderate PHG over follow up period (32\%, $12 \%$ and $8 \%$ at 0,6 and 12 months respectively in carvedilol group) and (40\%, $28 \%$ and $24 \%$ at 0,6 and 12 months respectively 
in propranolol group) .On other hand, in VBL group, there was statistically significant increase of severity of PHG over follow up period ( $32 \%$ , $32 \%$ and $48 \%$ at 0,6 and 12 months respectively). Varices were eradicated in $56 \%$ of patients after a mean of $4.24 \pm 1.39$ band sessions. Median time to eradication was 18 week (range, 8-36 weeks).

Incidence of bleeding ranged from $8 \%$ in carvedilol group to $12 \%$ in VBL group and $20 \%$ in propranolol but this difference was not statistically significant (table 2). Serum albumin best predicting incidence at cut off value less than $2.75 \mathrm{mg} / \mathrm{dl}$ with C-statistic $>0.73$ and $95 \%$ Confidence Interval (CI) $0.609-0.853$. The only variables that could significantly predict the probability of incidence of first variceal bleeding among all variables at randomization time were mild PHG and serum albumin $\leq 2.75 \mathrm{mg}$ (table $3)$.

Table (1): Child Pugh classification of the patients at randomization time.

\begin{tabular}{|c|c|c|c|c|c|c|c|}
\hline \multicolumn{2}{|c|}{} & $\begin{array}{c}\text { VBL } \\
\mathbf{n = 2 5}\end{array}$ & $\begin{array}{c}\text { Carvedilol } \\
\mathbf{n = 2 5}\end{array}$ & $\begin{array}{c}\text { Propranolol } \\
\mathbf{n = 2 5}\end{array}$ & $\begin{array}{c}\text { Total } \\
\mathbf{n = 7 5}\end{array}$ & \multirow{2}{*}{$\mathbf{X}^{\mathbf{2}}$} & \multirow{2}{*}{ P } \\
\hline \multirow{3}{*}{ Class n (\%) } & $\mathrm{A}$ & $9(36 \%)$ & $9(36 \%)$ & $10(40 \%)$ & $28(37.3 \%)$ & & \multirow{2}{*}{0.98} \\
\cline { 2 - 7 } & $\mathrm{B}$ & $6(24 \%)$ & $7(28 \%)$ & $7(28 \%)$ & $20(26.7 \%)$ & \multirow{2}{*}{0.39} & \\
\cline { 2 - 8 } & $\mathrm{C}$ & $10(40 \%)$ & $9(36 \%)$ & $8(32 \%)$ & $27(36 \%)$ & & \\
\hline
\end{tabular}

Table (2): Incidence of variceal heamorrhage among the treatment groups

\begin{tabular}{|c|c|c|c|c|c|c|}
\hline & $\begin{array}{c}\text { VBL } \\
\mathrm{n}=\mathbf{2 5}\end{array}$ & $\begin{array}{c}\text { Carvedilol } \\
n=25\end{array}$ & $\begin{array}{c}\text { Propranolol } \\
\quad n=25\end{array}$ & $\begin{array}{l}\text { Total } \\
\mathrm{n}=75\end{array}$ & $\mathbf{X}^{2}$ & $\mathbf{P}$ \\
\hline $\begin{array}{l}\text { Non bleeder } \\
\text { n }(\%)\end{array}$ & $\begin{array}{c}22 \\
(88 \%)\end{array}$ & $\begin{array}{c}23 \\
(92 \%)\end{array}$ & $\begin{array}{c}20 \\
(80 \%)\end{array}$ & $\begin{array}{c}65 \\
(86.7 \%)\end{array}$ & \multirow{2}{*}{1.61} & \multirow{2}{*}{0.45} \\
\hline $\begin{array}{l}\text { Bleeder } \\
\text { n }(\%)\end{array}$ & $\begin{array}{c}3 \\
(12 \%)\end{array}$ & $\begin{array}{c}2 \\
(8 \%)\end{array}$ & $\begin{array}{c}5 \\
(20 \%)\end{array}$ & $\begin{array}{c}10 \\
(13.3 \%)\end{array}$ & & \\
\hline
\end{tabular}

Table (3): Multilogistic Regression Analysis of variables at randomization time

\begin{tabular}{|l|c|c|c|}
\hline \multirow{2}{*}{} & \multicolumn{2}{|c|}{ 95 \% CI } & \multirow{2}{*}{ P value } \\
\cline { 2 - 3 } & Lower & Upper & 0.64 \\
\hline PHG mild & 0.144 & 22.918 & $0.01^{*}$ \\
\hline PHG moderate & 1.701 & 218.193 & 0.19 \\
\hline PHG marked & 0.318 & 317.670 & $0.01^{*}$ \\
\hline Albumin $\leq \mathbf{2 . 7 5} \mathbf{~ m g / d l . ~}$ & 1.863 & 188.462 & \\
\hline
\end{tabular}

$* \mathrm{P}<0.05$ significant

\section{DISCUSSION}

Carvedilol, a non-cardioselective beta-blocker, is more effective in reducing portal pressure than propranolol, however, there have been much need for clinical studies assessing the efficacy of carvedilol in primary prophylaxis [7].

Carvedilol was found to have lower bleeding rate than VBL and propranolol $(8 \%, 12 \%$ and $20 \%$ respectively) over treatment period of 12 months. This finding is in concordance with that reported by Tripathi et al. [8] who compared between carvedilol and VBL over longer treatment duration (median of 20 months) and found that carvedilol had lower bleeding rate than VBL (10\% and 23\% respectively). This confirms the efficacy of carvedilol.
In our study, no bleeding from band ulcer had occurred, mostly because of long interval between VBL endoscopy settings (2-4 weeks), which may explain the lower rate of variceal bleeding with VBL in our study than reported by Tripathi et al. [8] who implemented short intervals of 1 to 2 weeks between banding sessions.

The present study showed that Propranolol treatment had the highest bleeding rate (20\%). Perez-Ayuso et al. [9] compared between 2 treatment groups (propranolol versus VBL) and reported that propranolol had a significant higher rate than VBL $(25 \%$ versus. $12 \%$ respectively). On the other hand, Drastich et al. [10] reported lower bleeding rate with propranolol versus VBL (6 \% versus 5\%). This 
variation in bleeding rates could be explained by the predominance of Child Pugh class A and B patients in the study of Drastich et al. [10] .These finding indicates that propranolol has a better efficacy in less advanced liver cirrhosis and compensated cirrhosis.

In this study, moderate PHG at the start of the study and baseline serum albumin less than 2.75 $\mathrm{mg} / \mathrm{dl}$, were the only variables that could significantly predict the probability of incidence of 1st variceal bleeding among the three treatment groups. Others had reported that grade III varices could predict variceal bleeding [8].

Serum creatinine level in propranolol group showed statistically significant increase over the follow period $(1.23 \pm 0.29$ at start of the study versus $1.31 \pm 0.40 \mathrm{mg} / \mathrm{dl}$ at 12 months, $\mathrm{P}=0.02$ ). On the other hand, Serum creatinine was unaffected $(1.14 \pm 0.23$ versus $1.16 \pm 0.29 \mathrm{mg} / \mathrm{dl}$, $\mathrm{P}=0.21)$ in carvedilol group. These results agreed with that reported by Banares et al. [4] who found that the mean serum creatinine level was unaffected during a longer follow-up period. So this confirms the safety profile of carvedilol treatment on kidney function. The portal vein congestion index significantly decreased over the follow up period in both carvedilol group $(0.183$ \pm 0.09 at 0 time to $0.152 \pm 0.01$ at 12 months with $\mathrm{P}=0.009)$ and propranolol group $(0.185 \pm$ 0.09 at 0 time to $0.169 \pm 0.09$ at 12 months with $\mathrm{P}=0.01)$. However, there was no significant change in the mean CI in VBL group $(0.176 \pm 0.08$ at 0 time to $0.171 \pm 0.02$ at 12 months with $\mathrm{P}=0.86$ ). So both carvedilol and propranolol had a maintained decrease effect on CI which is correlated with presence and size of varices [11].

Carvedilol had significantly decreased the percentage of patients with varices grade III or IV over the follow up period (from $40 \%$ to $24 \%$ ). On the other hand, proranolol had no significant change in the percentage of patients with varices grade III or IV. This confirms the efficacy of carvedilol as portal hypotensive drug as recorded by Garcia-Tsao et al. [2]. Both carvrdilol and propranolol significantly decreased the percentage of patients with moderate $\mathrm{PHG}$ over follow up period ( $32 \%, 12 \%$ and $8 \%$ at 0,6 and 12 months respectively in carvedilol group) and $40 \%, 28 \%$ and $24 \%$ at 0,6 and 12 months respectively in propranolol group) .On other hand, in VBL group, there was statistically significant increase of severity of PHT over follow up period ( from $32 \%, 32 \%$ and $48 \%$ at 0,6 and 12 months respectively). These results insure the effects of carvedilol and propranolol on portal hypertension and on its complication unlike VBL which only treats varices with no effect on the underlying cause or the other complication of portal hypertension; furthermore, VBL had increased the severity of PHG. This may be due to the effect of eradication of $\mathrm{OV}$ collaterals on portal hypertension or PHG develops as a result of congestion caused by blockade of gastric blood drainage rather than by hyperemia[12]. The eradication rate in VBL group was $56 \%$ but other studies with larger numbers of patients and longer follow-up reported rates between $70 \%$ and $75 \%$ [8], [13].

\section{CONCLUSION}

Carvedilol is effective in preventing the $1^{\text {st }}$ variceal bleeding and it can be considered as a treatment option for primary prophylaxis of variceal bleeding in patients with liver cirrhosis and esophageal varices $\geq$ grade II in a single daily dose of $12.5 \mathrm{mg}$.

Funding: Non .

\section{Conflicts of interest: Non .}

Ethical approval: The protocol of the study was approved by the ethical committee of Faculty of Medicine, Zagazig University. Informed consents were obtained from all patients.

\section{REFERENCES}

1. Harry R, Windon J. Management of variceal bleeding. Curr Opin Crit Care 2002; 8: 164-70.

2. Garcia-Tsao G, Sanyal AJ, Grace ND, Carey W. Prevention and management of gastroesophageal varices and variceal hemorrhage in cirrhosis. HEPATOLOGY 2007; 46: 922.

3. Banares R, Moitinho E, Matilla A, Garcia-Pagan JC, Lampreave JL, Piera C, et al. Randomized Comparison of Long-Term Carvedilol and Propranolol Administration in the Treatment of Portal Hypertension in Cirrhosis. HEPATOLOGY 2002; 36: 1367-1373.

4. Banares R, Moitinho E, Matilla A. Carvedilol (Carv) vs. Propranolol (Prop) in the long term treatment of portal hypertension. J Hepatol 2000; 32(Suppl. 2): 6262.

5. Tripathi D, Therapondos G, Lui HF, Stanley AJ, Hayes PC. Haemodynamic effects of acute and chronic administration of low-dose carvedilol, a vasodilating beta-blocker, in patients with cirrhosis and portal hypertension. Aliment Pharmacol Ther 2002; 16(3): 373-80. 
6. Dean AG, Dean JA, Brendel KA. Epi - Info version 6.02 a word processing data base and statistics program for epidemiology on a microcomputer CD, Atlanta, Gorgia, USA. 2000 P: 620.

7. Tripathi D. The role of carvedilol in management of portal hypertension. Eur J Gastroenterol Hepatol 2010; 22: 905-911.

8. Tripathi D, Ferguson JW, Leithead JA, Mcavoy NC, Stanley AJ, Forrest EH, et al. Randomized controlled trial of carvedilol versus variceal band ligation for the prevention of the first variceal bleed. HEPATOLOGY 2009; 50: 825-833.

9. Perez-Ayuso RM, Valderrama S, Espinoza M, Rollán A, Sánchez R, Otarola F, et al. Endoscopic band ligation versus propranolol for the primary prophylaxis of variceal bleeding in cirrhotic patients with high risk esophageal varices. Ann Hepatol. 2010; 9(1):15-22.

10. Drastich P, Lata J, Petrtyl J, Bruha R, Prochazka V, Vanasek T, et al. Endoscopic variceal band ligation compared with propranolol for prophylaxis of first variceal bleeding. Ann Hepatol 2011; 10 (2):14-29.

11. Siringo S, Fabio P, Gianni Z, Blondil L Baumgartner U, Henke D et al. Influence of esophageal varices, spontaneous portal systemic shunts on post prandial hemodynamics. Am J Gastroenterol 2001; 96(2): 550.

12. Sarwar S, Khan AA, Alam A, Butt AK, Shafqat F, Malik K, et al. Effect of band ligation on portal hypertensive gastropathy and development of fundal varices. J Ayub Med Coll Abbottabad 2006; 18(1): 32-5.

13. Jutabha R, Jensen DM, Martin P, Savides T, Han SH, Gornbein J. Randomized study comparing banding and propranolol to prevent initial variceal hemorrhage in cirrhotics with high-risk esophageal varices. Gastroenterology 2005; 128:870-881. 